\title{
Type 2M and Type 2A von Willebrand Disease: Similar but Different
}

\author{
Emmanuel J. Favaloro, PhD, FFSC (RCPA $)^{1,2}$ Leonardo Pasalic, MBBS, FRACP, FRCPA ${ }^{1,2}$ \\ Jennifer Curnow, MBBS, FRACP, FRCPA, PhD ${ }^{1}$
}

${ }^{1}$ Departments of Clinical and Laboratory Haematology, Institute of
Clinical Pathology and Medical Research and Westmead Hospital,
Sydney Centres for Thrombosis and Haemostasis, Westmead, New
South Wales, Australia
2 Pathology West, NSW Health Pathology, New South Wales, Australia

Address for correspondence Emmanuel J. Favaloro, PhD, FFSC (RCPA), Haematology, Institute of Clinical Pathology and Medical Research, Sydney Centres for Thrombosis and Haemostasis, Westmead Hospital, Westmead, NSW 2145, Australia

(e-mail: emmanuel.favaloro@health.nsw.gov.au).

Semin Thromb Hemost 2016;42:483-497.

\begin{abstract}
Keywords

- von Willebrand disease

- 2A VWD

- $2 \mathrm{M} V W D$

- von Willebrand factor

Analogous to the differentiation between hemophilia $A$ and $B$, respectively, reflecting deficiency in factor VIII (FVIII) and FIX, and increasing being recognized as reflecting clinically different disorders, types $2 \mathrm{~A}$ and $2 \mathrm{M}$ von Willebrand disease (VWD) can also be shown to express both similarities and differences in their prevalence, genetic defects, laboratory test results, clinical features, and treatment responses. In this narrative review, we explore these two "subtypes" of type 2 VWD, identifying parallels and dissimilarities in various aspects of their presentation to clinicians and to scientists/ laboratories. This differential will become increasingly important as we strive to provide personalized approaches to future management of patients with VWD, particularly in the emerging landscape of recombinant von Willebrand factor.
\end{abstract}

Historically, the clinical presentation of hemophilia A and B has been considered "similar," with the distinction essentially being made by laboratory testing (deficiency in factor VIII [FVIII] and FIX, respectively). However, although hemarthroses and muscle hematomas represent common types of bleeding in both disorders, with similarities in age of symptom onset and bleed frequency in patients with severe deficiency, there are significant differences in the type of genetic defects, prevalence of the disorders, and incidence of treatment complications, such as rates of inhibitor development, anaphylaxis, and nephrotic syndrome. ${ }^{1}$ Current thinking thus points to hemophilia $\mathrm{B}$ as being a potentially less severe hemophilic disorder than hemophilia $\mathrm{A}^{1}$

Likewise, types $2 \mathrm{~A}$ and $2 \mathrm{M}$ von Willebrand disease (VWD) demonstrate both similarities and differences in their prevalence, genetic defects, laboratory test results, clinical features, and treatment responses. In this narrative review, we explore these two "subtypes" of type 2 VWD, identifying parallels and dissimilarities in various aspects of their presentation to clinicians and to scientists/laboratories.

published online May 5, 2016
Issue Theme Controversies in Inherited Bleeding Disorders; Guest Editors: Antonio Coppola, MD, Massimo Franchini, MD, and Annarita Tagliaferri, MD.

\section{Overview of VWD}

VWD is considered to be the most common inherited bleeding disorder, and is caused by deficiencies and/or defects in the plasma protein von Willebrand factor (VWF). ${ }^{2-4}$ The true prevalence of VWD is unknown; although epidemiological studies estimate a value up to $1 \%$ of the general population, a more conservative prevalence based on clinical presentations of symptomatic patients would be around 1 in 10,000 (0.01\%). ${ }^{4}$

VWD is autosomally inherited and most commonly arises due to mutation/s in VWF, mapped at 12p13.3. VWD diagnosis requires the presence of a personal (typically lifelong) and family history of primarily mucocutaneous bleeding, as well as laboratory evidence of absence, deficiency, or defect in VWF. $^{2-9}$

According to the current classification scheme, ${ }^{2}$ there are six types of VWD (-Table $\mathbf{1}$ ), characterized on the basis of quantitative deficiencies of VWF (VWD types 1 and 3) or qualitative defects in VWF (type 2 VWD), which may or may not be also associated with a quantitative deficiency of VWF.

Copyright $\odot 2016$ by Thieme Medical Publishers, Inc., 333 Seventh Avenue, New York, NY 10001, USA. Tel: +1(212) 584-4662.
DOI http://dx.doi.org/ 10.1055/s-0036-1579641. ISSN 0094-6176. 
Table 1 Classification scheme for von Willebrand disease, phenotypic presentation, and clinical considerations

\begin{tabular}{|c|c|c|c|}
\hline $\begin{array}{l}\text { VWD } \\
\text { type }\end{array}$ & Description & Phenotypic presentation & Clinical considerations \\
\hline 1 & $\begin{array}{l}\text { Partial quantitative } \\
\text { deficiency of VWF }\end{array}$ & $\begin{array}{l}\text { Low levels of VWF, with VWF functional } \\
\text { concordance (i.e., ratio of functional VWF/ } \\
\text { VWF:Ag approximates unity) }\end{array}$ & $\begin{array}{l}\text { Severity of bleeding associated with level of } \\
\text { VWF (the lower the level, the more severe } \\
\text { the bleeding presentation). Therapy } \\
\text { generally entails use of DDAVP or VWF } \\
\text { concentrate }\end{array}$ \\
\hline $2 \mathrm{~A}$ & $\begin{array}{l}\text { Decreased VWF-dependent } \\
\text { platelet adhesion and a } \\
\text { selective deficiency of high- } \\
\text { molecular-weight (HMW) } \\
\text { VWF multimers }\end{array}$ & $\begin{array}{l}\text { Loss of HMW VWF. Usually low levels of } \\
\text { VWF, with VWF functional discordance } \\
\text { (i.e., ratios of RCo/Ag and } \mathrm{CB} / \mathrm{Ag} \\
\text { typically }<0.7 \text { ) }\end{array}$ & $\begin{array}{l}\text { Severity of bleeding associated with level } \\
\text { and functionality of VWF. Therapy generally } \\
\text { entails use of VWF concentrate. DDAVP is } \\
\text { effective in a subset of patients }\end{array}$ \\
\hline $2 B$ & $\begin{array}{l}\text { Increased affinity of VWF for } \\
\text { platelet glycoprotein 1b }\end{array}$ & $\begin{array}{l}\text { Low to normal levels of VWF, typically with } \\
\text { VWF functional discordance (i.e., ratios of } \\
\text { RCo/Ag and CB/Ag generally }<0.7) \text {, loss of } \\
\text { HMW VWF and (mild) thrombocytopenia. } \\
\text { Atypical cases may not show this pattern. } \\
\text { Defined by enhanced responsiveness in a } \\
\text { RIPA assay }\end{array}$ & $\begin{array}{l}\text { Generally presents with moderate or } \\
\text { moderately severe bleeding. Therapy } \\
\text { generally entails use of VWF } \\
\text { concentrate. DDAVP may be considered } \\
\text { contraindicated in these patients }\end{array}$ \\
\hline $2 \mathrm{M}$ & $\begin{array}{l}\text { Decreased VWF-dependent } \\
\text { platelet adhesion without a } \\
\text { selective deficiency of high- } \\
\text { molecular-weight (HMW) } \\
\text { VWF multimers }\end{array}$ & $\begin{array}{l}\text { Low to normal levels of VWF, usually with } \\
\text { VWF functional discordance detected by } \\
\text { RCo/Ag generally }<0.7 \text {, but relatively } \\
\text { normal CB/Ag ratio. HMW VWF present, } \\
\text { but multimers may show other } \\
\text { abnormalities }\end{array}$ & $\begin{array}{l}\text { Severity of bleeding associated with level } \\
\text { and functionality of VWF. Therapy generally } \\
\text { entails use of VWF concentrate. DDAVP is } \\
\text { effective in a subset of patients }\end{array}$ \\
\hline $2 \mathrm{~N}$ & $\begin{array}{l}\text { Markedly decreased binding } \\
\text { affinity for factor VIII }\end{array}$ & $\begin{array}{l}\text { Defined by VWF:FVIIIB assay, with low } \\
\text { FVIIIB/VWF ratios }\end{array}$ & $\begin{array}{l}\text { Generally present with moderate or } \\
\text { moderately severe bleeding and may have a } \\
\text { phenotype more typically seen in mild or } \\
\text { moderate hemophilia A (due to factor VIII } \\
\text { deficiency): soft tissue, joint, and urinary } \\
\text { bleeding, and bleeding after invasive } \\
\text { procedures. Therapy generally entails use } \\
\text { of VWF concentrate }\end{array}$ \\
\hline 3 & $\begin{array}{l}\text { Virtually complete } \\
\text { deficiency of VWF }\end{array}$ & $\begin{array}{l}\text { Typically defined by VWF levels }<2 \mathrm{U} / \mathrm{dL} \\
\text { and FVIII }<10 \mathrm{U} / \mathrm{dL} \text {. }\end{array}$ & $\begin{array}{l}\text { Most severe form of VWD, and patients } \\
\text { show bleeding symptoms similar to } \\
\text { moderate or severe hemophilia A. Therapy } \\
\text { generally entails use of VWF concentrate } \\
\text { (DDAVP is not effective) }\end{array}$ \\
\hline
\end{tabular}

Abbreviations: $\mathrm{CB} / \mathrm{Ag}$, collagen binding to antigen ratio; DDAVP, desmopressin; FVIII, factor VIII; HMW, high molecular weight; RCo/Ag, ristocetin cofactor to antigen ratio; RIPA, ristocetin induced platelet agglutination (/aggregation); VWD, von Willebrand disease; VWF, von Willebrand factor; VWF:Ag, von Willebrand factor antigen; VWF:FVIIIB, VWF FVIII binding assay.

Note: Classification scheme derived and adapted from Sadler et al. ${ }^{2}$

VWF is a large, complex protein and has essential roles in both primary and secondary hemostasis (see the reports by Sadler et al, ${ }^{2}$ Yee and Kretz, ${ }^{10}$ and Peyvandi et al ${ }^{11}$ for extensive reviews). In vivo biosynthesis of VWF is limited to endothelial cells and megakaryocytes. ${ }^{12,13}$ VWF is initially "constructed" with a prepropolypeptide configuration, comprising a 22amino acid signal peptide ("pre"), a 741-amino acids propolypeptide, and the remaining mature VWF subunit of 2,050 amino acids. After synthesis in the endoplasmic reticulum of endothelial cells, the signal peptide is cleaved, and oligosaccharide chains are added using N-linked glycosylation. Dimerization of pro-VWF molecules then occurs through "tail-totail" intersubunit carboxyl termini disulfide bond formation. The N-linked oligosaccharide chains are further modified in the Golgi apparatus by a series of glycosidases and glycosyltransferases to produce complex-type carbohydrates, and additional oligosaccharide chains are added to each VWF monomer. Multimerization of pro-VWF dimers then takes place in the post-Golgi, involving another round of disulfide bond formation near the amino-termini of the subunits. Additional modifications in the trans-Golgi network include the proteolytic removal of the large VWF propeptide, which is known to play an essential role in the multimer assembly (since deletion of the propeptide abolishes multimerization), but which is not required for VWF function in plasma.

Mature VWF then enters the plasma as a series of oligomers containing a variable numbers of subunits, ranging from a minimum of 2 to a maximum of around 40 , with the largest (high molecular weight [HMW]) multimers having molecular weights in excess of 20,000 kDa. The VWF is released from endothelium into the plasma through a direct constitutive secretory pathway, or tubularized and stored in internal 
organelles known as Weibel-Palade bodies, to be released later as required.

Upon exocytosis, rapid unfolding of VWF into ultra-long strings occurs, with VWF "docking" on the endothelial cells to permit adhesion to platelets. Thus, VWF stored within Weibel-Palade bodies of endothelial cells is composed of the largest multimeric species, ultra-large VWF (UL-VWF), which are usually not observed in normal plasma because of ADAMTS-13 (a disintegrin-like and metalloprotease with thrombospondin type 1 motif, member 13) cleavage at the time of secretion. Regulated secretion of stored VWF from endothelial cells occurs in response to several physiologically relevant agonists, including histamine and thrombin. VWF multimers and the VWF propeptide are secreted together in 1:1 stoichiometric amounts, but subsequently have different fates; the propeptide dissociates from VWF multimers and circulates independently as a noncovalent homodimer with a very short half-life of $\sim 2$ hours.

The D'-D3 domains of VWF represent the binding site for FVIII, and mutations in this region can lead to type 2N VWD. The D'-D3 domains are also possible binding sites for Pselectin, which has been determined to anchor newly released UL-VWF to the surface of activated endothelial cells and thus present the VWF cleavage site to ADAMTS-13. The A1 domain represents the binding site for the platelet glycoprotein Ib (GPIb) receptor, as well as binding sites for heparin, sulfated glycolipids, the snake venom botrocetin, and some forms of collagen, notably type VI. The A2 domain contains the ADAMTS-13 cleavage site. The A3 domain is the binding site for fibrillar collagen types I and III, and the C1 domain comprises the RGD (Arg-Gly-Asp) sequence, being the binding site for the platelet integrin $\alpha \operatorname{Ilb} \beta 3$ (-Fig. 1).
Type 1 VWD is usually inherited in an autosomal-dominant pattern and defines a quantitative deficiency of VWF in which the plasma VWF is otherwise functionally normal. In normal practice, type 1 VWD is identified by a low level of VWF antigen (VWF:Ag), but with similar levels of functional VWF (usually identified using VWF ristocetin cofactor [VWF: RCo] and collagen binding [VWF:CB]; - Table 2). FVIII levels fall in parallel with VWF, but is normally present at levels higher than ( $\sim 1.5$ times that of $)$ VWF.

Type 3 VWD has an autosomal recessive pattern of inheritance and defines the most severe defect, essentially describing an absence of VWF. In normal practice, type 3 VWD is identified by a low level of VWF:Ag $<2$ to $5 \mathrm{U} / \mathrm{dL}$ (with actual cut-off value depending on a given laboratory's assay sensitivity limits; - Table 2 ).

In type 2 VWD patients, characterized by various qualitative defects of VWF, the level of VWF protein may be normal or reduced, and FVIII levels may also be low or normal. Most cases of type 2 VWD (including 2A, 2M, and $2 B)$ are inherited in an autosomal-dominant pattern. Most cases of type 2 VWD (again including 2A, 2M, and 2B) also display a more complete penetrance of the disease than type 1 VWD. This is because some patients with type 1 VWD may carry a gene defect but may not display clinical symptoms, referred to as incomplete penetrance. In contrast, patients with type $2 \mathrm{~A}, 2 \mathrm{M}$, or $2 \mathrm{~B}$ VWD gene defects are very likely to display clinical symptoms.

Type 2A VWD describes an absence or deficiency in HMW $\mathrm{VWF}^{2}$ representing the forms of VWF that are most biologically active. Type $2 A$ VWD is identified by loss of HMW VWF on multimer analysis or by coincident low VWF:RCo/Ag and low VWF:CB/Ag ratios (-Table 2 ).

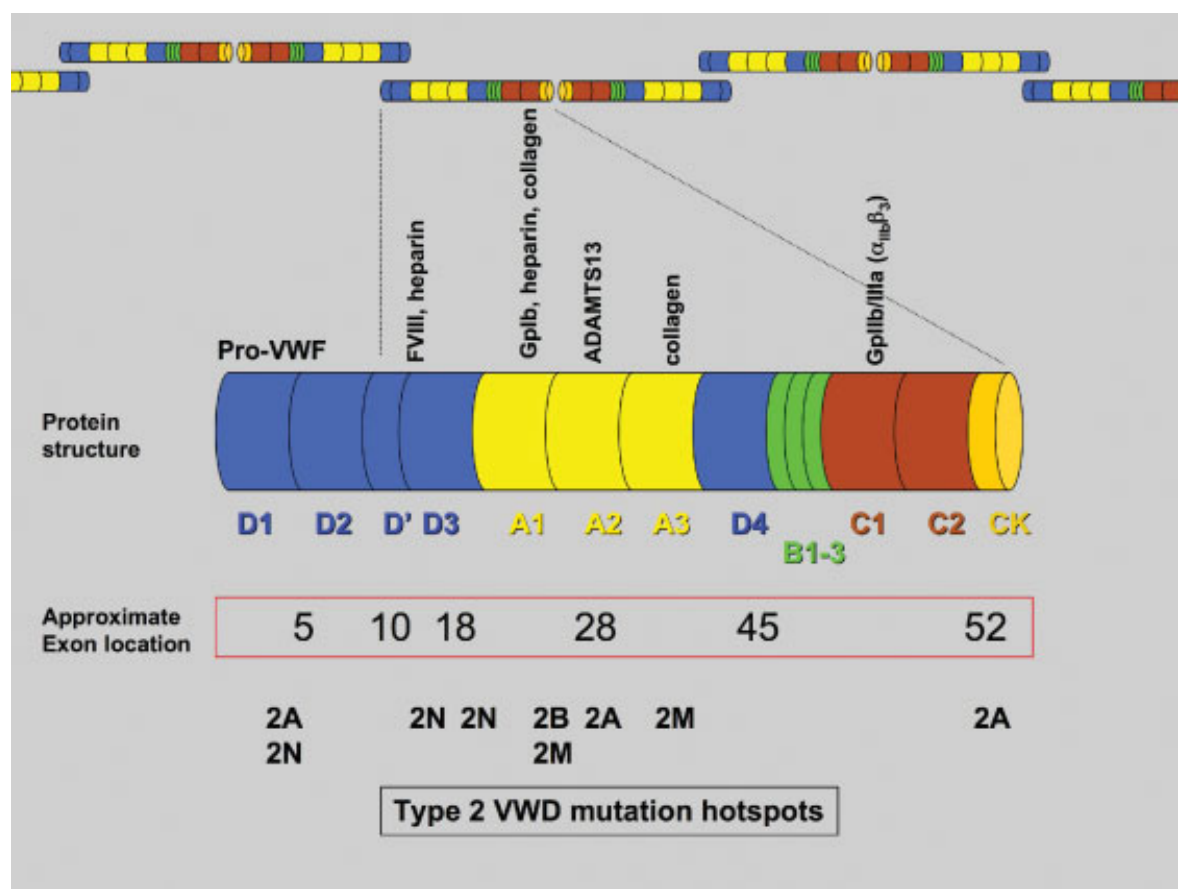

Fig. 1 Protein structure of von Willebrand factor (VWF) showing domain position (middle of figure), ligand binding sites (above domain), and formation into multimers (top of figure). The approximate VWF exon location corresponding to the protein domain, as well as type 2 von Willebrand disease (VWD) mutation hotspots, are shown at the bottom of the figure. 

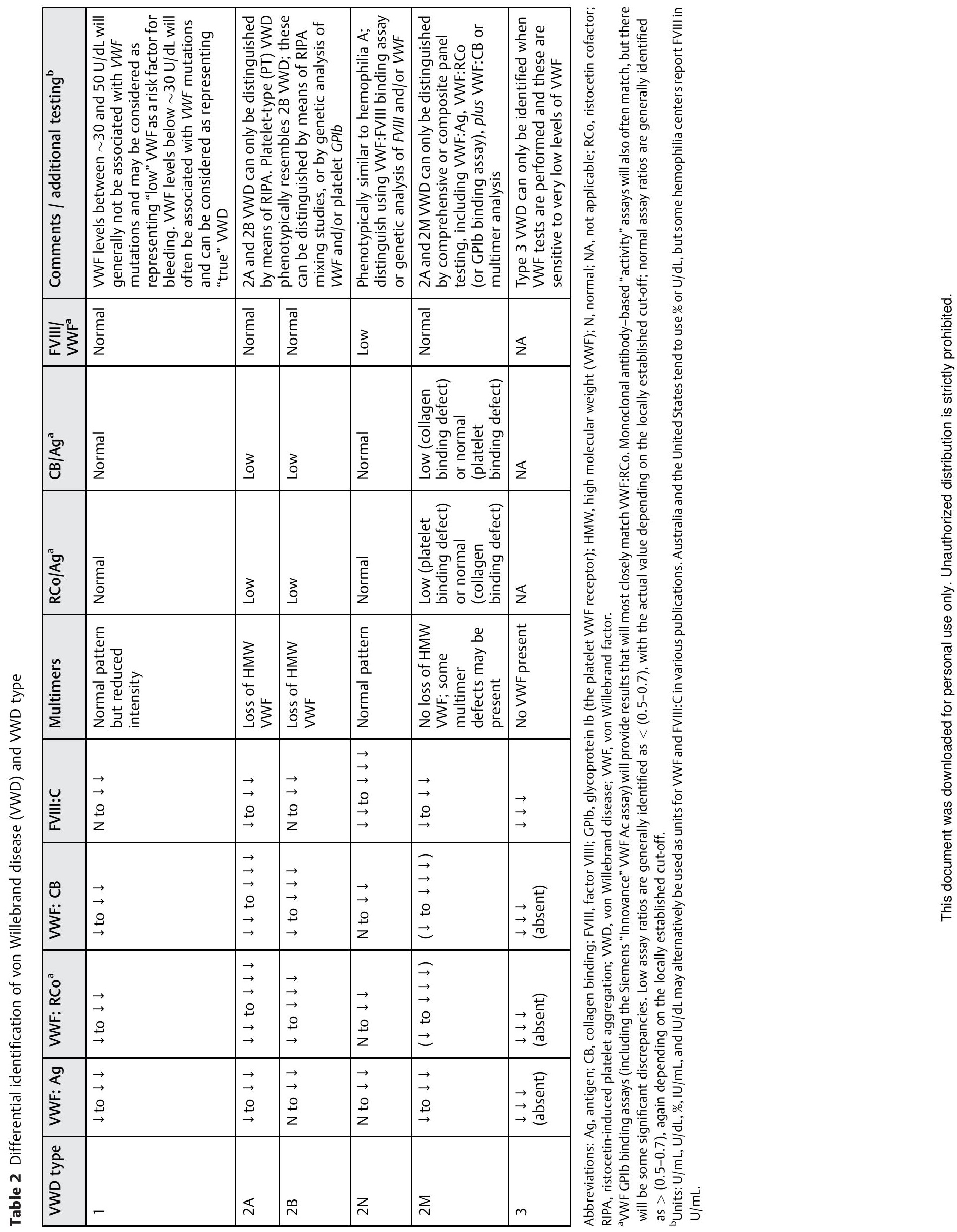
Type 2B VWD describes patients in which VWF is hyperadhesive, ${ }^{2}$ which is then cleared from the circulation with "spontaneously" bound platelets, leading to a loss of HMW VWF and also sometimes (mild) thrombocytopenia. Type 2B VWD is identified by elevated response to ristocetin in a ristocetin-induced platelet aggregation (RIPA) assay, and in general these patients also present with reduced HMW VWF and thus coincident low VWF:RCo/Ag and low VWF:CB/Ag ratios (i.e., ratios similar to type $2 \mathrm{~A} V W D$; - Table 2).

Type 2N VWD has an autosomal recessive inheritance pattern and reflects a defect in $\mathrm{VWF}$ that does not permit proper binding to FVIII. ${ }^{2}$ Like type 3 VWD, this leads to early proteolysis and loss of plasma FVIII, with consequent bleeding symptoms similar to those of mild or moderate hemophilia A. In normal practice, $2 \mathrm{~N}$ VWD is identified using a VWF:FVIII binding assay or by genetic analysis of $V W F$, although these patients may be identified earlier because of reduced plasma FVIII:C/VWF:Ag ratios (- Table 2).

Type 2M VWD describes various qualitative defects not associated with loss of HMW VWF. ${ }^{2}$ In normal practice, type $2 \mathrm{M} \mathrm{VWD}$ is generally identified by low VWF:RCo/Ag ratio, but no loss of HMW VWF on multimer gels, or in some laboratories, including ours, by the combination of low VWF:RCo/Ag but normal VWF:CB/Ag (- Table 2). This concept is expanded on in later sections.

\section{Relative Incidence of VWD Types}

\section{Types 1 and 3 VWD}

In developed countries, type $1 \mathrm{VWD}$ is generally identified as being the most common VWD type, representing over $70 \%$ of all identified VWD cases, although most of these patients present with only mildly reduced levels of VWF and with mild bleeding symptoms. ${ }^{4}$ Conversely, type 3 VWD is the least common VWD type in developed countries, usually representing $<5 \%$ of VWD cases (and perhaps representing only $\sim 1-5$ cases per million population). This situation, however, is reversed in developing countries, with type 3 VWD more commonly identified than type $1 \mathrm{VWD}$. This is due to several factors, including a greater frequency of consanguineous relationships (leading to existence of more index cases of type $3 \mathrm{VWD}$ ) and the relatively high cost of treatment and low availability of diagnosis and treatment centers (thus, only patients with severe VWD are likely to seek clinical care).

\section{Type 2 VWD}

The incidence of type 2 VWD tends to be intermediate between the "extremes" of types 1 and $3 \mathrm{VWD}$, and generally represents a range from $\sim 10$ to $30 \%$ of identified VWD cases, although relative frequency of VWD types, as identified by different centers, varies according to the reporting center. ${ }^{4}$ This differential is depicted in - Fig. $\mathbf{2}$, which shows data from a previously published evaluation. ${ }^{4}$ This depiction of differentially reported incidence is not meant to be definitive, but it does inform on the high variability of reported data, which in large part is determined by the ability of laboratories to appropriately differentiate between different types of VWD. This is particularly evident for type 2 VWD, which tends to represent the diagnostically most challenging forms of VWD.
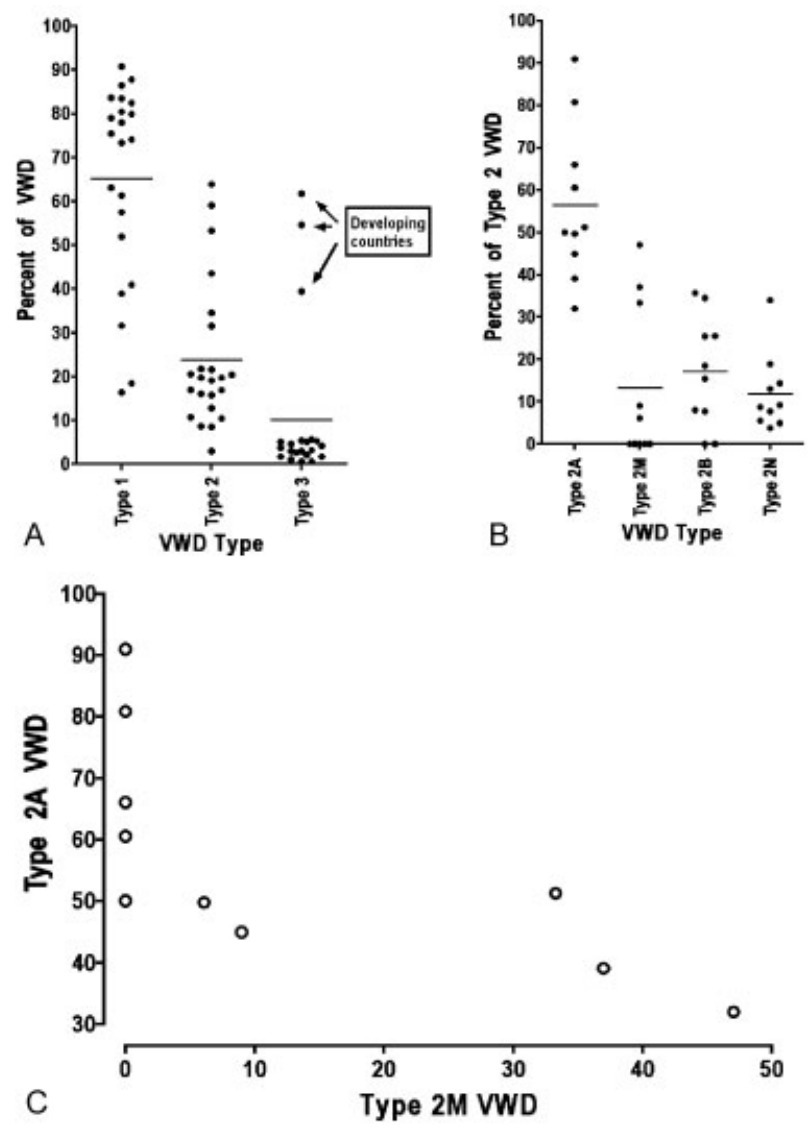

Fig. 2 (A) Differentially reported incidence of types 1, 2, and 3 von Willebrand disease (VWD) according to reporting center shown as percentage of VWD cases. (B) Differentially reported incidence of types $2 \mathrm{~A}, 2 \mathrm{M}, 2 \mathrm{~B}$, and $2 \mathrm{~N} V W D$ according to reporting center shown as percentage of type 2 VWD cases. (C) Relative reported incidence of types $2 \mathrm{~A}$ and $2 \mathrm{M} V W D$ from individual centers shown as percentage of type 2 VWD cases (the more type 2A VWD cases reported, the fewer $2 \mathrm{M}$ cases reported). Data from Favaloro. ${ }^{4}$

Type 2AVWD is the most commonly identified and reported type $2 \mathrm{VWD}$ ( - Fig. 2B), generally representing $>50 \%$ of all type 2 VWD. In contrast, types $2 \mathrm{~N}$ and $2 \mathrm{~B} V W D$ are well recognized to be rare type 2 VWD forms, each representing generally $<20 \%$ of type 2 VWD (or perhaps 5-10 cases per million population). Relevant to the current review, type $2 \mathrm{M}$ is either a rare or a common form of type $2 \mathrm{VWD}$, depending on the center reporting the data. ${ }^{4}$ The vast majority of centers either fail to identify type $2 \mathrm{M}$ VWD or identify it as a rare disorder $(<10 \%$ of all type 2 VWD cases). However, a few centers, in particular from two geographies (Europe and Australia), identify that type 2M VWD is a common form of type $2 \mathrm{VWD}$, perhaps as common as 2A VWD. ${ }^{14-19}$ However, unlike the case of type 1 versus 3 VWD, where geographic discordance in incidence appears to at least partially reflect the "true" relative incidence, with $2 \mathrm{~A}$ versus $2 \mathrm{M}$ VWD, the differentially reported incidence does not appear to be a "true" differential incidence, but rather simply a geographic disparity based on variable clinical/laboratory identification. Thus, it would appear that many clinicians/laboratories are simply failing to identify type $2 \mathrm{M}$ VWD as such, instead (mis) identifying these cases as either type 1 or $2 \mathrm{~A}$ VWD. 


\section{Evidence for "Misidentification" of Type 2M VWD and Its Under-Recognition}

Evidence for the contention that $2 \mathrm{M}$ VWD is both highly misidentified and under-recognized comes from a variety of sources. As a prime example, we can highlight the outcome of the large "type 1 VWD" genetic studies undertaken in the mid2000s. In one such study, comprising 150 index cases derived from 14 VWD treatment centers in 9 European countries and originally identified as type $1 \mathrm{VWD}$, a subgroup of 57 patients were later identified to have abnormal multimer patterns and showed a high prevalence of VWF gene mutations $(94 \%$, or 54 of 57 cases). ${ }^{20}$ In contrast, fewer mutations could be identified (55\%, or 51 of 93 cases) in those cases with qualitatively normal VWF, characteristic of type 1 VWD. The eventual conclusion was that about one-third of the originally identified and recruited "type 1 VWD cases" would need to be reconsidered as being type 2 (these were later primarily classified as type $2 \mathrm{M}$ ); thus, only the remaining group could be considered "true" type 1 VWD. Studies from two other groups have found similar results. ${ }^{21-25}$ Thus, of a total of 194 families submitted to the Canadian type 1 VWD study, referred from 13 tertiary care, academic health centers across Canada, 12 families were later reclassified as type 2 VWD after reevaluation of the hemostasis studies from both the referral clinic and the central laboratory. ${ }^{21}$ In a subsequent analysis, a further 10 index cases were found to have either loss of HMW VWF (i.e., 2A VWD) or abnormal triplet patterns using multimer analysis (i.e., 2M VWD), and a further 11 cases with normal multimers were found to have low VWF:RCo/Ag ratios $(<0.6)$ (i.e., 2M VWD). ${ }^{22}$ In total, then, 33/194 (17\%) index cases originally identified as type $1 \mathrm{VWD}$ could be reclassified as type 2 VWD (and primarily 2M VWD) following study reevaluation. Such difficulties in the differential identification of type 1 and 2M VWD were later better recognized by the Canadian group. ${ }^{23}$ Finally, another study from the United Kingdom Haemophilia Centre Doctors Organization (UKHCDO) comprising 40 families, recruited through the national network of comprehensive care hemophilia centers affiliated to UKHCDO, were diagnosed to have type $1 \mathrm{VWD} .^{24} \mathrm{~A}$ family could be included in this study if a consultant hematologist at a hemophilia center had made a diagnosis of type 1 VWD according to previous UKHCDO guidelines, ${ }^{25}$ there were recorded VWF:RCo levels of below $50 \mathrm{U} / \mathrm{dL}$, the ratio of VWF:RCo/Ag was greater than 0.7 , the plasma VWF multimer profile was normal, individuals had a history of significant mucocutaneous bleeding, and there was more than one family member with a diagnosis of type 1 VWD. ${ }^{24}$ However, following a review of submitted cases by the authors, six families (13.6\%) were re-diagnosed to have type 2 VWD.

Additional evidence for continued misidentification of type 2M VWD as another type of VWD comes from recent External Quality Assessment (EQA) data. ${ }^{26,27}$ In the most recent exploration from our geography, our EQA provider sent participants samples from patients with type 2M VWD and these were more often misidentified as not being 2M VWD (70.6\% of occasions) than correctly identified as $2 \mathrm{M} \mathrm{VWD}$ (29.4\% of occasions). ${ }^{27}$ One type $2 \mathrm{M}$ case, giving a median of $49 \mathrm{U} / \mathrm{dL}$ VWF:Ag, was more often misidentified as type $2 \mathrm{~A} / 2 \mathrm{~B}$ VWD (46.7\%) than $2 \mathrm{M}$ (34.8\%). Another 2M case, giving a median of $189 \mathrm{U} / \mathrm{dL} \mathrm{VWF}: \mathrm{Ag}$, ${ }^{28}$ was instead more often misidentified as being normal (not VWD)
(36.4\%), with identifications of type 2A/2B VWD (13.6\%) also represented. In comparison, errors in identification of HMW VWF-reduced samples (i.e., 2A/2B VWD) only averaged $11.5 \%$, a figure similar to those identified in earlier reports from this EQA program for 2B VWD. ${ }^{29}$

\section{Genetic Considerations}

As previously noted, VWD most commonly arises due to mutation/s in VWF. However, mutations are not commonly identified in type 1 VWD unless plasma VWF levels fall below $\sim 30 \mathrm{U} / \mathrm{dL}$. $^{3,20-22,24}$ In contrast, mutations are often identifiable in type 2 VWD cases, with evident hotspots according to the gene locality and the arising structural protein change (-Fig. 1). For example, most mutations yielding 2N VWD occur within exons 18 to 24 (and representing the D domain where FVIII binds to VWF). ${ }^{30}$ In contrast, most mutations yielding types 2A, 2B, and 2M VWD are located within exon 28 (and representing the three A domains where VWF binds to platelet GPIb or collagen, as well as the ADAMTS13 cleavage site).$^{30}$ Although types $2 \mathrm{~A}, 2 \mathrm{~B}$, and $2 \mathrm{M}$ VWD mutations can occur anywhere within exon 28, there do appear to be separate "hotspots," as evidenced by an analysis of the online VWD database (-Fig. 3). ${ }^{30}$ Interestingly, however, type $2 \mathrm{~A}$ VWD causing mutations can supposedly occur at the 2B VWD mutation "hotspot," and type 2M VWD causing mutations can supposedly occur at the 2A VWD mutation "hotspot," and so on (-Fig. 3). Moreover, some mutations have been reported to cause "both" $2 \mathrm{~A}$ and $2 \mathrm{M}$ VWD, whereas others have been reported to cause "both" $2 \mathrm{~B}$ and $2 \mathrm{M}$ VWD, and others reported to cause "both" $2 \mathrm{~A}$ and $2 \mathrm{~B}$ VWD, etc. (-Table 3 ). It is likely that at least some of the above cases will represent misidentification of VWD type, or at least a perspective of differential identification (i.e., different laboratories will simply differentially call the same VWD case as either $2 \mathrm{~A}$, $2 \mathrm{~B}$, or $2 \mathrm{M}$ VWD based on their particular case work-up).

Attempts to differentially distinguish type 2M VWD on the basis of genetic mutations and phenotypic laboratory test patterns have been attempted and reported by several authors. ${ }^{18,19,23,31}$ For example, Penas et al ${ }^{18}$ reported on a group of patients with the genetic mutation p.R1374C, responsible for type 2M VWD according to their study, but often misdiagnosed as type 1 VWD by others, and representing a high frequency in their geography of northwestern Spain (Galicia). They reported that the VWF:CB (using type I collagen) did not identify the defective platelet binding of the mutated VWF, highlighting the added discriminatory value of the VWF:CB as a supplementary assay to VWF:RCo to the diagnosis of VWD.

\section{Laboratory Phenotypic Considerations}

\section{Type 2M and Type 2A VWD: A Similar Disorder as Phenotypically Identified by Most Laboratories}

Types 2B and 2N VWD have "specific" phenotypic assays that permit their "definitive" identification. Type 2B VWD is characterized by enhanced binding to platelet GPIb, which is most often explored by use of RIPA. Classically, 2B VWD is defined by a response to low-dose ristocetin $(\leq 0.5 \mathrm{mg} / \mathrm{dL})$ in this assay, ${ }^{2,3,32}$ 


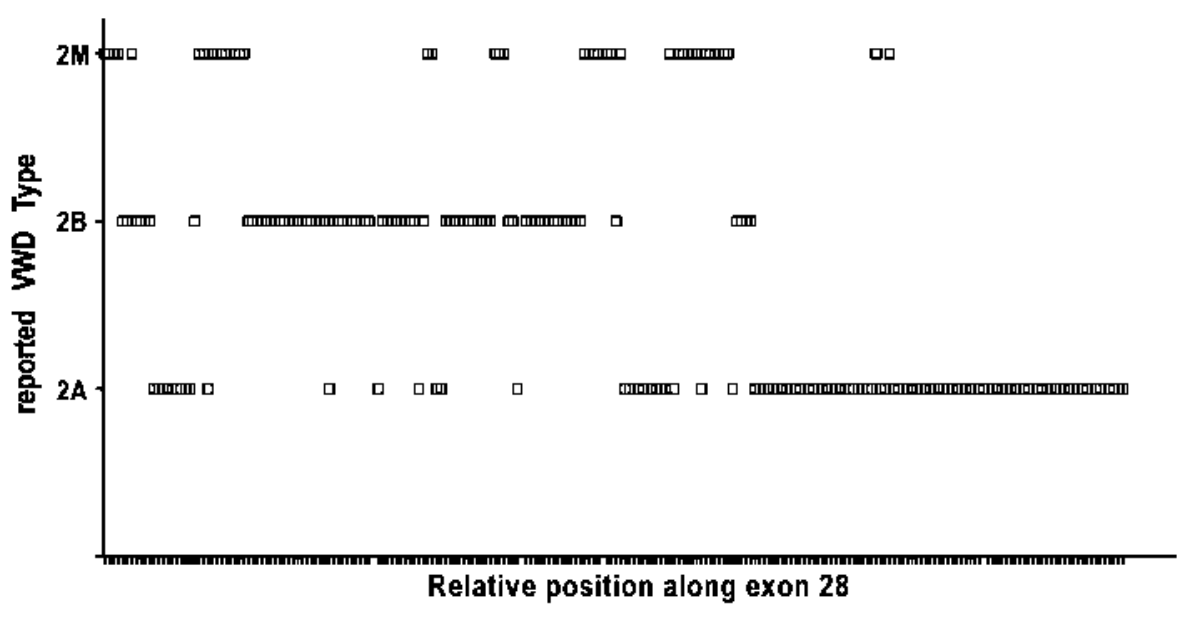

Fig. 3 Reported type 2 von Willebrand disease (VWD) mutations in exon 28. Relative position along exon 28 shown on $x$-axis, and whether this mutation was reported for a type $2 \mathrm{~A}, 2 \mathrm{M}$, or $2 \mathrm{~B}$ mutation is identified by the symbols and $\mathrm{y}$-axis. Note the relatively high number of reported type $2 \mathrm{~A}$ mutations at the end of exon 28, and the relatively high number of reported type 2B mutations at the start of exon 28. Fewer mutations have been reported for type 2M VWD, but this is likely due at least in part to under-recognition of type 2M VWD. Note also some overlap in reported types, so that 2A and 2M VWD have also been reported in the 2B VWD "hotspot," and so on. Some of these events may reflect subtype misidentification of some cases. Data from online VWD database. ${ }^{30}$

although some $2 \mathrm{~B}$ VWD cases only show enhanced response at levels closer to $0.7 \mathrm{mg} / \mathrm{dL}^{33}$ There are other alternate assays available, albeit less often utilized, but essentially, it is difficult to "diagnose" a case of VWD as being type 2B VWD without evidencing enhanced GPIb binding (unless genetic analysis confirms a known 2B VWD-causing mutation, albeit with the caveats identified in section "Genetic Considerations"). Similarly, type $2 \mathrm{~N}$ VWD is characterized by reduced binding of VWF to FVIII, which is most often explored by use of the VWF-FVIII binding assay (VWF:FVIIIB). ${ }^{2,3,34}$ Again, it is difficult to establish a "diagnosis" of type 2N VWD without showing reduced VWFFVIII binding (unless genetic analysis confirms a known $2 \mathrm{~N}$ VWD-causing mutation).

The situation with types 2A and 2M VWD is different. Both types $2 \mathrm{~A}$ and $2 \mathrm{M}$ VWD are qualitative VWD disorders characterized by relative loss of VWF activity, and will yield similar levels of most phenotypic laboratory VWD markers (-Table 2; - Fig. 4). Thus, 2A and 2M VWD will both express similar levels of VWF:Ag (low or normal), similar levels of FVIII: C (also low or normal), and similar levels of VWF:RCo (low in both), yielding also low VWF:RCo/Ag ratios in both. These three assays (VWF:Ag, VWF:RCo, and FVIII:C) comprise the most commonly performed VWD diagnostic test panel, and as they yield values essentially indistinguishable between $2 \mathrm{~A}$ and $2 \mathrm{M}$ VWD, it is not possible to differentiate between $2 \mathrm{~A}$ and $2 \mathrm{M}$ VWD if these are the only assays utilized as the laboratory VWD test panel. Moreover, laboratories using such test panels will in general preferentially identify cases yielding test patterns consistent with either 2A or 2M VWD as being 2AVWD, ${ }^{27}$ simply because of reporting bias (widespread perception that $2 \mathrm{~A}$ VWD cases are more common than $2 \mathrm{M}$, and greater recognition of $2 A$ VWD as a type 2 VWD subtype).

\section{Type 2M and Type 2A VWD: Phenotypically Different in Some Laboratories}

However, types $2 \mathrm{~A}$ and $2 \mathrm{M}$ VWD are also phenotypically different by laboratory testing, and there are tests that enable distinction between the two diagnoses. One of these (type $2 \mathrm{~A}$ VWD) is characterized by relative loss of HMW VWF (due to decreased production or increased proteolysis), whereas the other (type 2M VWD) is not associated with (a "substantial") loss of HMW VWF, but rather the loss of specific activity/ activities due to specific VWF mutations causing reduction in, for example, GPIb binding or collagen binding, or in some case both GPIb and collagen binding, and in other potential cases other defects. ${ }^{2,3}$ The previous quality (no "substantial" loss of HMW VWF in 2M VWD) is important, because some forms of type 2M may show a "minor" loss of HMW VWF, which may cause some laboratories to identify these as 2A VWD, and others will reflect that this is mentioned in the classification criteria $^{2}$ and call these cases 2M VWD.

Although definitive (differential) diagnosis of $2 \mathrm{M}$ and $2 \mathrm{~A}$ VWD would therefore require performance of VWF multimers, to investigate whether or not there is a ("substantial") loss of HMW VWF (loss = 2A VWD; no "substantial" loss = 2M VWD), this is in itself problematic. First, VWF multimers are only performed by a small proportion of VWD testing laboratories, ${ }^{35}$ usually only between 1 and 25\% depending on the geography; in any case, certainly far more laboratories do not perform multimer testing than do perform multimer testing. Second, several EQA providers have reported on the high level of "diagnostic" error associated with performance of the multimer assay. One such study reported an overall average error rate of $15 \%$ associated with VWF multimer performance, with $5 \%$ of laboratories reporting a loss of HMW VWF in normal samples, $18 \%$ reporting a loss of HMW VWF in type 1 VWD samples, and $18 \%$ reporting a normal multimer pattern in HMW-reduced type 2 VWD. $^{36}$ Another study was more concerning, ${ }^{37}$ associating performance of VWF multimers with a $23 \%$ error rate for normal samples and an up to $52 \%$ error rate in type $1 \mathrm{VWD}$. These error rates are generally higher than error rates associated with performance of phenotypic laboratory tests, which usually average around $10 \%^{26,27,29}$ Data reflecting errors associated with use on VWF multimers from "expert centers" are not 
Table 3 Do the same or similar mutations really cause different types of VWD?

\begin{tabular}{|c|c|c|}
\hline VWD type reported & DNA change & Protein change $^{a}$ \\
\hline Type 2M & c.3686_3797conNG_001212.3:g.6417_6528 & p.[(V1229G; N1231T; S1263 = ; P1266Q)] \\
\hline Type 2M & c.3686_3797conNG_001212.3:g.6417_6528 & p.[(V1229G; N1231T; S1263 = ; P1266Q)] \\
\hline Type 2M & c.3686_3797conNG_001212.3:g.6417_6528 & p.[(V1229G; N1231T; S1263 = ; P1266Q)] \\
\hline Type 2B & c.3686_3797conNG_001212.3:g.6417_6528 & p. $[(V 1229 G ; N 1231 T ; V 1245=; S 1263=; P 1266 L)]$ \\
\hline Type 2B & c.3797C > A & p.(P1266Q) \\
\hline Type 2M & c.3797C > A & p.(P1266Q) \\
\hline Type 2B & c.3797C $>T$ & p.(P1266L) \\
\hline Type 2B & c. $3835 \mathrm{C}>\mathrm{A}$ & p.(V1279I) \\
\hline Type 2M & $c .3835 G>A$ & p.(V1279I) \\
\hline Type 2M & c.3835G > A & p.(V1279I) \\
\hline Type 2A & c.3835G $>\mathrm{T}$ & p.(V1279F) \\
\hline Type $2 \mathrm{~A}$ & c.3923G > A & p.(R1308H) \\
\hline Type 2B & $c .3923 G>C$ & p.(R1308P) \\
\hline Type 2B & c.3940G >C & p.(V1314L) \\
\hline Type 2A & c.3940G > T & p.(V1314F) \\
\hline Type 2M & c.3943C > T & p.(R1315C) \\
\hline Type 1 (type 2A) & c.3943C > T & p.(R1315C) \\
\hline Type 2B & c. $4010 \mathrm{C}>\mathrm{T}$ & p.(P1337L) \\
\hline Type $2 \mathrm{~A}$ & c. $4010 \mathrm{C}>\mathrm{T}(+\mathrm{c} .823 \mathrm{~T}>\mathrm{C})$ & p.(P1337L) \\
\hline Type 2B (type 2A) & c. $4010 \mathrm{C}>\mathrm{T}$ & p.(P1337L) \\
\hline Type 2M & c. $4120 \mathrm{C}>\mathrm{T}$ & p.(R1374C) \\
\hline Type 1 (type 2A/2M) & c. $4120 \mathrm{C}>\mathrm{T}$ & p.(R1374C) \\
\hline Type 2A & c. $4120 \mathrm{C}>\mathrm{T}$ & p.(R1374C) \\
\hline Type 2A / 2M & c. $4120 \mathrm{C}>\mathrm{T}$ & p.(R1374C) \\
\hline
\end{tabular}

Note: Data are from the von Willebrand disease (VWD) database, ${ }^{30}$ and restricted to exon 28 . Some identical mutations and some similar mutations have been reported in the same location as leading to different types of VWD by different researchers. This is likely to be due to differential identification of type 2 VWD subtypes rather than these mutations actually causing different VWD types.

a Letters refer to amino acid codes: C, cysteine; G, glycine; F, phenylalanine; H, histidine; I, isoleucine; L, leucine; N, asparagine; P, proline; Q, glutamine; $\mathrm{R}$, arginine; $\mathrm{S}$, serine; $\mathrm{T}$, threonine; $\mathrm{V}$, valine.

reassuring either. The previously mentioned genetic type 1 VWD studies $^{20-22,24}$ misidentified around 15 to $20 \%$ of type 2 VWD cases as type $1 \mathrm{VWD}$, and multimer analysis comprised at least a proportion of the initial case work up for many of these misidentified cases. ${ }^{38}$ Whether associated errors reflect methodological issues or interpretation of VWF multimers is not clear, and both may contribute to the error rate.

This diagnostic problem can therefore in part be mitigated by use of a more comprehensive test panel that includes the VWF:CB assay, to help generate differential test patterns, as well as using surrogate measures for multimer analysis. ${ }^{18,19,39-42}$ Thus, in type 2A VWD, loss of HMW VWF will be captured by evidence of combined low VWF:RCo plus low VWF:CB, as well as combined discordant (low) VWF:RCo/Ag and VWF:CB/Ag, given that both VWF: RCo and VWF:CB are sensitive to loss of HMW VWF. In contrast, most cases of type 2M VWD comprise VWF mutations that lead to loss of GPIb binding (identified by VWF:RCo and other GPIb-binding assays), but often these mutations have limited or no effect on collagen binding, 

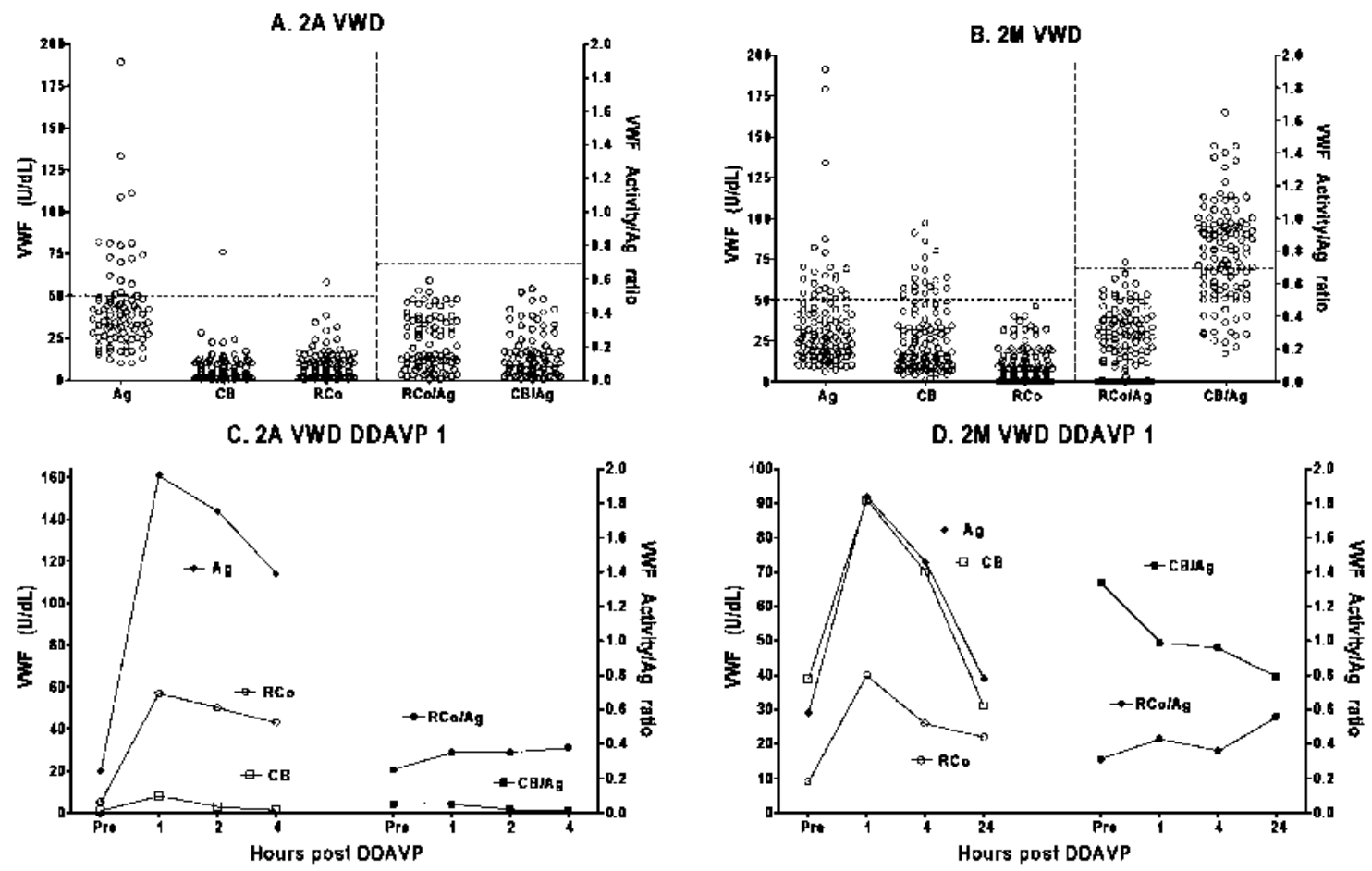

E. 2A VWD DDAVP 2

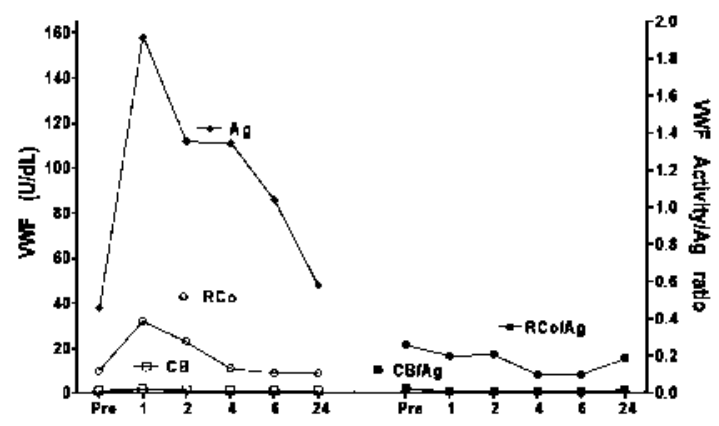

F. 2W WWD DDAVP 2

G. 2A WWD DDAVP 3

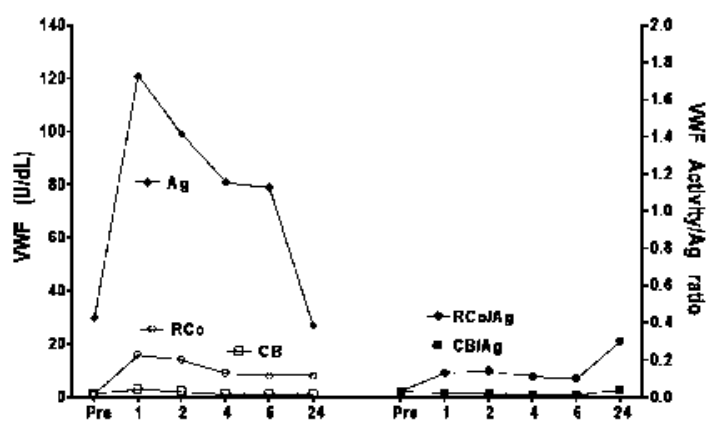

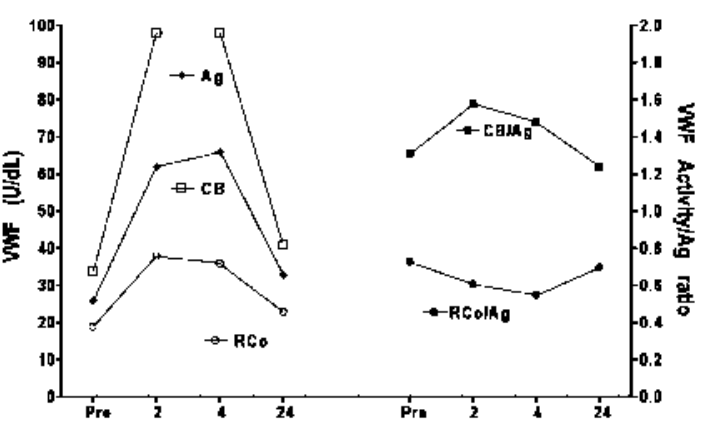

H. 2M WWD DDAVP 3

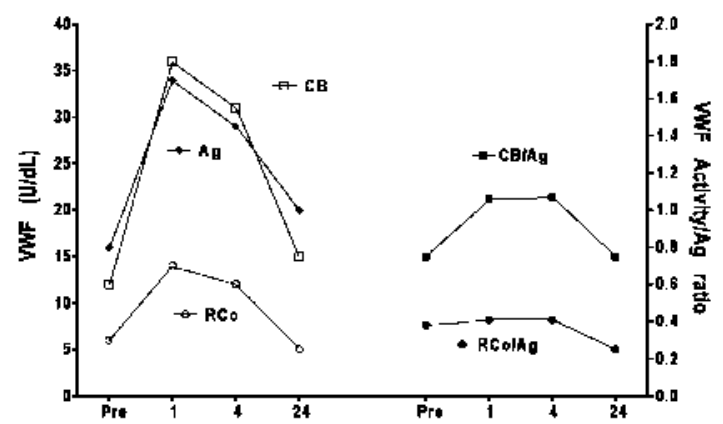

Fig. 4 Phenotypic test patterns identified in types 2A and 2M VWD. (A, B) The dashed horizontal lines indicate the typical normal/abnormal cutoff values of $50 \mathrm{U} / \mathrm{dL}$ for VWF parameters and 0.7 for assay ratios. Both $2 \mathrm{~A}$ and $2 \mathrm{M}$ VWD in general show low (or occasionally normal) levels of von Willebrand factor (VWF) antigen (VWF:Ag) and correspondingly lower (discordant) levels of VWF ristocetin cofactor (VWF:RCo), with resultant low VWF:RCo/VWF:Ag (RCo/Ag) ratios (generally $<0.7)$. VWF collagen binding is also correspondingly low in type 2A VWD, with resultant low VWF:CB/ VWF:Ag $(\mathrm{CB} / \mathrm{Ag})$ ratios (generally <0.7). However, in type $2 \mathrm{M}$ VWD, VWF:CB may be less affected by the VWF mutation and yield values more similar to VWF:Ag, and thus $\mathrm{CB} / \mathrm{Ag}$ ratios may be normal (i.e., $>0.7$ ), or at least higher than $\mathrm{RCo} / \mathrm{Ag}$ ratios. These test patterns can also be evidenced from results of desmopressin (DDAVP) trials (C-H). Thus, substantial increments in VWF:Ag (and FVIII:C [not shown]) occur in response to DDAVP in both $2 A(C, E, G)$ and $2 M(D, F, H) V W D$ cases. Conversely, VWF:RCo fails to substantially increase in both $2 A$ and $2 \mathrm{M} V W D$ in response to DDAVP. Differentially, however, VWF:CB does not generally increase in type 2A VWD, but often increases in type 2M VWD. Thus, as a general rule, low $\mathrm{RCo} / \mathrm{Ag}$ plus low $\mathrm{CB} / \mathrm{Ag}$ ratios post-DDAVP "equals" $2 \mathrm{~A} V W D$ and low $\mathrm{RCo} / \mathrm{Ag}$ plus normal CB/Ag ratios post-DDAVP "equals" $2 \mathrm{M}$ VWD. Data from our laboratory. 
and thus VWF:CB/Ag ratios are usually normal, or at least closer to normal than VWF:RCo/Ag. 4,5,9,14,16,18,19,26,27,29

Thus, laboratories can utilize the differential patterns of low VWF:RCo/Ag plus low VWF:CB/Ag as most likely identifying HMW VWF reduction (and thus a type $2 \mathrm{~A}$ or $2 \mathrm{~B}$ or platelet-type [PT] VWD, which can then be differentiated with RIPA assessment), whereas a pattern of low VWF:RCo/ Ag plus normal VWF:CB/Ag ratio is inconsistent with HMW VWF reduction (providing that both VWF:RCo and VWF:CB are confirmed to be sensitive to the presence or loss of HMW VWF) and thus must be identifying a type 2M VWD. Naturally, not all cases presenting with low VWF:RCo/Ag plus low VWF: $\mathrm{CB} / \mathrm{Ag}$ will be $2 \mathrm{~A}$ or $2 \mathrm{~B}$ VWD (some will be $2 \mathrm{M}$ VWD that affects both GPIb and collagen binding), but most cases will be 2A or 2B VWD. Conversely, a consistently low VWF:RCo/Ag ratio plus normal VWF:CB/Ag ratio is highly sensitive and specific for type 2M VWD. 4,5,9,14,16,18,19,26,27,29,38-48

In our laboratory, we can usually demonstrate such differential patterns and we have previously validated this approach for the differential identification of types $2 \mathrm{~A}$ versus $2 \mathrm{M}$ VWD, as previously extensively reported. ${ }^{4,5,14,26-29,31,38-48}$ An example of the distinction is provided in - Fig. 4. In our laboratory, we also supplement our differential diagnostic approach with the results of any available desmopressin (DDAVP) trials, which are often conducted in these patients to assess responsiveness as an aid to management. ${ }^{43-46}$ Again, several examples of the differential patterns observed in types $2 A$ versus $2 M$ VWD are shown in - Fig. 4. Here, DDAVP tends to yield substantial increments in VWF:Ag (and FVIII:C [not shown]) in both 2A and 2M VWD cases. Conversely, DDAVP fails to yield substantial increments in VWF:RCo in both 2A and 2M VWD cases. The differential in response is seen in the VWF:CB pattern, which does not generally increase in type $2 \mathrm{~A} V W D$, but does often increase in type $2 \mathrm{M}$ VWD. Thus, an unclear type $2 \mathrm{~A} / 2 \mathrm{M}$ case may be diagnostically clarified post-DDAVP as low VWF:RCo/Ag plus low $\mathrm{VWF}: \mathrm{CB} / \mathrm{Ag}$ ratios post-DDAVP (=2AVWD) versus low $\mathrm{VWF}$ : $\mathrm{RCo} / \mathrm{Ag}$ plus normal VWF:CB/Ag ratios post-DDAVP (=2M VWD).

\section{Conclusion for Laboratory Phenotype}

Phenotypically, types 2A and 2M VWD show great similarity using the common or core laboratory test panels, meaning FVIII, VWF:Ag, and VWF:RCo assays. Thus, if laboratories restrict their test panels to these three assays, they will often misidentify type 2M VWD as either 2AVWD (with low VWF:RCo/Ag ratio) or type 1 VWD (with normal VWF:RCo/Ag ratio). Performance of VWF multimers may assist the discrimination of types $2 \mathrm{~A}$ and $2 \mathrm{M}$ VWD; however, these assays are rarely performed, and when performed are themselves associated with a high error rate. Addition of a VWF:CB assay aids in the discrimination of $2 \mathrm{~A}$ and 2M VWD according to the differential test patterns observed in these cases (-Fig. 4). Unfortunately, there remain several barriers to incorporation of a VWF:CB to the test panel in many laboratories. These include: (1) an unfortunate general lack of recognition of the added value of VWF:CB to laboratory diagnosis of VWD; (2) the additional cost of performing an extra test, with possibility that this may not be reimbursed by government funding; (3) the lack of regulatory-cleared assays in certain geographies (for example, there is no Food and Drug
Administration-cleared assay in the United States). ${ }^{35}$ Finally, not all VWF:CB assays are identical, and some have better utility than others. ${ }^{42,47,48}$ Thus, not only should laboratories incorporate a VWF:CB into their test repertoire, but also they need to incorporate the "right" VWF:CB.

\section{Clinical and Management Considerations}

\section{Type 2M and Type 2A VWD: Similar Clinical Disorders with Similar Management}

In simplistic terms, type 2M and 2A VWD are clinically similar because they are both disorders of primary hemostasis and their management involves replacement of VWF. As discussed in the section "Laboratory Phenotypic Considerations," there is significant variability in laboratory classification of types $2 \mathrm{~A}$ and $2 \mathrm{M}$ VWD; one under-recognized consequence is a relative lack of prospective data in wellcharacterized cohorts, which can then be utilized to compare clinical features and treatment responses in the less frequent VWD subtypes. Thus, since many cases of 2M VWD have likely been "misdiagnosed" as type $2 \mathrm{~A}$ (or even type 1 ) VWD, there is a historical melding of clinical features in these VWD subtypes, especially 2A and 2M VWD. As our knowledge of specific genetic mutations giving rise to particular laboratory phenotypes grows, the pathophysiological mechanisms underlying VWD subtypes will be better understood and ultimately we may be able to predict differences in clinical manifestations and subsequently choose more specific treatments for individual VWD subtypes. At present, clinical descriptions and treatment guidelines remain very similar for $2 \mathrm{~A}$ and $2 \mathrm{M} \mathrm{VWD}^{3}$

Type 2A and 2M VWD may have normal or reduced levels of VWF:Ag and FVIII, but they both have a qualitative defect evidenced by reduced VWF:RCo, which indicates impaired interaction with the platelet GPIb complex and distinguishes them from type 1 VWD with an isolated quantitative defect. The clinical bleeding diathesis of VWF disorders is related to the degree of VWF deficiency and the type or severity of the VWF defect. Although the type of VWD influences the clinical phenotype in general, bleeding is typically of mucocutaneous type, including epistaxis, oral cavity bleeding, gastrointestinal bleeding, and menorrhagia, due to impaired VWF-dependent platelet adhesion in both $2 \mathrm{~A}$ and $2 \mathrm{M}$ VWD. ${ }^{49}$ In many of these patients, the level of FVIII is normal, and thus therapy should in general aim to only correct the missing functional VWF.

DDAVP administration triggers release of VWF and FVIII from endothelial cells. ${ }^{50,51}$ In type 1 VWD, cellular VWF is usually normal and thus in the majority of these patients it may be used as first-line therapy for minor surgery and bleeding. However, DDAVP is only effective in a proportion of type $2 \mathrm{~A}$ and $2 \mathrm{M}$ VWD patients. Observations from a large Italian registry showed response rates of 26 and 33\%, respectively. ${ }^{15}$ Consequently, it is necessary to undertake a DDAVP trial to determine an individual's pattern of response to DDAVP, although the response pattern is consistent within families, so that a parent's response may be used to predict that of an affected child. ${ }^{50}$ A test dose of 0.3 $\mu \mathrm{g} / \mathrm{kg}$ in $50 \mathrm{~mL}$ normal saline administered intravenously 
over 30 minutes is assessed by performing preinfusion testing of FVIII:C, VWF:Ag, and VWF:RCo (and in our laboratory also VWF:CB and platelet function analyzer, PFA-100/200 $)^{43,44,52}$ and repeat testing is done at 1 hour, 2 to 4 hours, and 24 hours postinfusion. There are alternate routes of DDAVP administration available in some countries, including subcutaneous and nasal preparations., ${ }^{3,52}$ These may also require a different dose of administration. Responders show a two- to fivefold increase from baseline and levels remain above $30 \mathrm{U} / \mathrm{dL}$ by 4 hours postinfusion unless VWF and/or FVIII clearance is significantly increased, but by 24 hours levels generally return to baseline. ${ }^{3,50}$ Adverse effects of DDAVP infusion are similar for both $2 \mathrm{~A}$ and $2 \mathrm{M}$ VWD and include facial flushing, hypertension or hypotension, tachycardia, headache, gastrointestinal upset, and hyponatremia, rarely complicated by seizures. DDAVP should be avoided in patients with increased risk for cardiovascular and cerebrovascular disease due to case reports of arterial thromboembolism. ${ }^{3}$ In circumstances where DDAVP is ineffective, response is inadequate, or its use is contraindicated, VWF concentrates are given intravenously, to treat or prevent bleeds, and efficacy is monitored clinically and by laboratory testing using the same tests as used for VWD diagnosis. ${ }^{3}$

Current VWF replacement therapy involves use of the same locally available concentrate for all types of VWD irrespective of the underlying VWF defect or VWF/FVIII deficiency. Currently available therapies contain both plasma-derived VWF and FVIII concentrates with a variable proportion of VWF/FVIII in products available in different geographic locations. ${ }^{52,53}$ This has important implications for therapeutic management, particularly for types $2 \mathrm{~A}$ and $2 \mathrm{M}$ VWD, when FVIII levels may be normal. Some concentrates have relatively high, and others relatively low, proportional levels of FVIII, and few concentrates are essentially FVIII deficient or only contain VWF. Similar differences in the level of HMW VWF between different VWF concentrates can also be identified. ${ }^{52,53}$ Treatment protocols for different geographic regions with respect to their specific concentrate products are summarized in our recent review. ${ }^{52}$ Pharmacokinetic studies are also used to optimize individual therapy. Laboratory tests for VWF:RCo and VWF:CB are more appropriate measures of the efficacy of replacement therapies than FVIII:C levels in types $2 \mathrm{~A}$ and $2 \mathrm{M}$ VWD. ${ }^{5}$

The development of recombinant human VWF (rVWF) may overcome limitations of plasma-derived products, including the availability of plasma donors, potential for viral transmission, variable product composition (including deficiency of HMW VWF multimers in some), and allergic reactions associated with extraneous plasma proteins. Vonicog alfa is an rVWF product synthesized in a Chinese hamster ovary cell line and has recently been tested in two clinical trials in patients with severe VWD. ${ }^{54,55}$ In a recent phase I dose escalation study, a single $50 \mathrm{IU} / \mathrm{kg}$ dose of rVWF-rFVIII appeared safe with no anaphylaxis, no thrombotic events, and no inhibitor development. Endogenous ADAMTS-13 was able to proteolyse the UL-VWF multimers of rVWF. ${ }^{54}$ Minor adverse events of tremor, pruritus, psychomotor hyperactivity, hypertension, nausea, dizziness, and variable sP-selectin values were noted. The rVWF appeared to show enhanced stabilization of endogenous FVIII and a longer terminal half-life. Gill et al have recently reported results of a phase III study of the safety, efficacy, and pharmacokinetics of rVWF with or without rFVIII for the treatment of clinical bleeding. ${ }^{55} \mathrm{All}$ bleeding episodes were successfully treated and a single infusion was sufficient in $81.8 \%$ of cases. Endogenous FVIII was stabilized for a prolonged period indicating that rFVIII infusions may not be required after a first dose or for type $2 \mathrm{~A}$ and type $2 \mathrm{M}$ patients with normal FVIII levels; then, rVWF could potentially be administered alone enabling individualization of therapy.

Prophylaxis is rarely required in type $2 \mathrm{~A}$ and type $2 \mathrm{M}$ VWD patients but may be commenced in patients with recurrent spontaneous bleeding. ${ }^{49} \mathrm{~A}$ separate chapter on prophylaxis in VWD is available elsewhere in this issue of the journal. ${ }^{56}$

Antifibrinolytic agents impair fibrinolysis by inhibition of plasmin generation and are useful adjunctive therapies in both $2 \mathrm{~A}$ and $2 \mathrm{M}$ VWD patients with recurrent mucocutaneous bleeding. ${ }^{3}$ Other beneficial adjunctive therapies useful in both these VWD subtypes include an oral contraceptive agent or the Mirena, a levonorgestrel-releasing intrauterine device, and iron therapy for women with menorrhagia. ${ }^{57}$ Aspirin and nonsteroidal anti-inflammatory agents should be avoided in all patients with VWD since these agents impair platelet function, worsening the defect in primary hemostasis. In case reports, inhibition of angiogenesis by thalidomide has been reported to reduce refractory angiodysplasia-related bleeding. Most patients required a dose of at least $100 \mathrm{mg}$ daily over a minimum period of 4 months. ${ }^{58}$

\section{Type 2M and Type 2A VWD: Clinically Different Disorders That Perhaps Should Be Managed Differently?}

As discussed previously, there are many similarities in the clinical features and management of these VWD subtypes; however, there are also several differences. Type 2M VWD describes various qualitative defects not associated with loss of HMW VWF. The pathophysiological mechanisms underlying type $2 \mathrm{~A} V W D$ vary with different genetic mutations and may be subclassified as group I mutations in which production of HMW multimers is impaired or group II in which synthesis and release of multimers is normal but they show increased susceptibility to ADAMTS13 proteolysis..$^{59,60}$ Type 2M VWD shows both a normal multimeric pattern and normal ADAMTS13-mediated proteolysis. ${ }^{61}$ Castaman et al reported a 2-year prospective study comparing clinical bleeding risk in 46 type $2 \mathrm{~A}$ patients and 61 type $2 \mathrm{M}$ VWD patients, all well characterized, including a standardized bleeding score, multimer analysis, and genetic analysis. ${ }^{49}$ FVIII and VWF:RCo values were similar in the two groups; however, baseline bleeding scores were higher in type $2 \mathrm{~A}$ patients, despite the fact that their VWF:Ag values were also higher. Type $2 \mathrm{~A}$ patients were also more likely to require treatment for spontaneous bleeding during the 2-year observation 
period with an incidence of $107 / 100$ (95\% confidence interval [CI], 88.3-131) patient years compared with 40/100 (95\% CI, $30-53$ ) patient years. This study suggests that type $2 \mathrm{~A}$ VWD may be a clinically more severe disease. Gastrointestinal bleeding was more common in type $2 \mathrm{~A} \mathrm{VWD}$, occurring in $36.9 \%$ patients compared with $3.3 \%$ patients with type $2 \mathrm{M}$ VWD. In acquired VWD associated with aortic stenosis, HMW multimers are lacking due to shear stress of blood flow across the valve, and the condition is also strongly associated with angiodysplasia, suggesting the HMW multimers may be particularly important in this type of gastrointestinal bleeding. ${ }^{62}$ Although the mechanisms are unproven, this may partially explain the differences seen in gastrointestinal bleeding between type 2A and type 2M VWD.

Kunicki et $\mathrm{al}^{63}$ examined the major haplotypes of seven candidate genes (GP1BA, ITGA2B, ITGB3, GP6, VWF, FGB, and IL6) but found that only genetic differences in expression of ITGA2B encoding integrin subunit $\alpha 2$ of platelet collagen receptor were associated with bleeding phenotype in type 2 VWD. Favaloro et al also raised the question of whether the increased gastrointestinal bleeding may represent a failure of VWF-collagen interaction based on the different pathophysiology in these two VWD subtypes. ${ }^{64}$

Treatment modalities have been discussed above; however, there is one study suggesting that although responses to DDAVP are highly variable, they are generally better in type $2 \mathrm{M}$ than $2 \mathrm{~A}$ VWD. ${ }^{65}$ Since the molecular defect in group 1 variants of $2 \mathrm{~A}$ VWD results in impaired synthesis and secretion of VWF, this may partially explain the reduced response to DDAVP compared with type 2M VWD as this agent acts by increasing secretion of VWF. DDAVP may be less effective if secretion is already impaired by the underlying genetic defect.

Also related to DDAVP responsiveness is the recognized differential pattern seen in types $2 \mathrm{~A}$ and $2 \mathrm{M}$ VWD, as previously highlighted. Thus, although VWF:Ag and FVIII:C show good increments in both $2 \mathrm{~A}$ and $2 \mathrm{M}$ VWD post-DDAVP, and VWF:RCo fails to show any substantial increment in both $2 \mathrm{~A}$ and $2 \mathrm{M} \mathrm{VWD}$, by including VWF:CB testing in the postDDAVP protocol, this will often show an increment in type 2M VWD but not in type $2 \mathrm{~A}$ (-Fig. 4). ${ }^{43-47}$

As partially explored above, there are substantial differences in the composition of different VWF concentrates. Different production techniques for VWF concentrates can affect the retention or loss of HMW VWF, the most adhesive or functional forms of VWF. A concentrate containing HMW VWF would provide greater adhesive hemostatic efficacy than one relatively devoid of HMW VWF and would be the ideal choice of therapy for type $2 \mathrm{~A} V \mathrm{VWD}$, since it would directly replace the specific absence of HMW multimers. However, "replacement" of HMW VWF may be less important in type 2M VWD, since these forms of VWF are not substantially missing in type 2M VWD cases, which instead are suffering qualitative defects associated with the VWF mutation. Thus, although current treatment of $2 \mathrm{~A}$ and $2 \mathrm{M}$ VWD is similar and entails the same replacement VWF concentrates, this may not be ideal, nor might it be the case in a future VWD treatment landscape, where use of recombinant products may eventually permit tailoring of therapy to the disorder. ${ }^{66}$ Laboratory testing of concentrates uses surrogate markers to provide an estimate of the level of "specific" VWF activity (VWF:RCo/Ag or VWF:CB/Ag ratios). This may also become more important in the future with the advent of tailored therapy. Finally, as mentioned above, the availability of tailored rVWF concentrates may provide even greater clinical benefit to type $2 \mathrm{~A}$ patients, since they have the potential to specifically replace the missing HMW multimers. ${ }^{66}$

\section{Conclusion for Clinical Management}

With the improvement in laboratory recognition and classification of type $2 \mathrm{~A}$ and $2 \mathrm{M} \mathrm{VWD}$, better characterized patient cohorts are being reported and evidence is emerging of some differences in clinical manifestations of these two conditions. However, current treatment remains largely similar with a minority of patients responsive to DDAVP and the majority requiring biological therapy with VWF concentrates still including FVIII in variable ratios, as well as potentially reflecting products with loss of HMW VWF. ${ }^{52,53}$ The advent of rVWF concentrates may change this in the near future. ${ }^{66}$

\section{Final Conclusion and Future Perspectives}

As discussed in this narrative review, types $2 \mathrm{~A}$ and $2 \mathrm{M}$ VWD reflect similar but also different bleeding disorders. These are largely summarized in - Table $\mathbf{4}$. We, and others, believe there are sufficient differences in laboratory test results to clearly differentiate most cases of type $2 \mathrm{~A}$ and $2 \mathrm{M}$ VWD. 4,5,9,14,16,18,19,26,27,29,38-48 This differential can be achieved using VWF multimer analysis; however, most laboratories do not perform multimer analysis because of text complexity and requirement for specialized equipment. Moreover, when performed, there is a high error rate associated with use of VWF multimers, and so laboratories performing these tests may still often misidentify $2 \mathrm{M}$ VWD. Our own diagnostic strategy (outlined in - Fig. 5) largely uses the differential test patterns of VWF:RCo versus VWF:CB to differentiate between qualitative defect (type 2 VWD) VWF samples expressing loss of HMW VWF (2A, 2B, or PT VWD) versus $2 \mathrm{M}$ VWD. In summary, low VWF: $\mathrm{RCo} / \mathrm{Ag}$ plus low VWF:CB/Ag suggests loss of HMW VWF, whereas low VWF: $\mathrm{RCo} / \mathrm{Ag}$ but normal VWF:CB/Ag is incompatible with a loss of HMW VWF and must be a type 2M VWD. This strategy presumes that the VWF:CB assay in use is sensitive to loss of HMW VWF, which we know our method to be, based on extensive characterization. ${ }^{4,5,14,26-29,31,38-48}$ In our experience, this differential is further accentuated in DDAVP testing (see - Table 2 and -Fig. 4 ).

Naturally, it is important to also recognize that, analogous to VWF level in type $1 \mathrm{VWD}$, some patients will be on an HMW multimer continuum between $2 \mathrm{~A}$ and $2 \mathrm{M}$ and therefore relatively more difficult to categorize, even with the extended diagnostic panel with VWF:CB assay.

Clinically, types 2A and 2M VWD may show broadly similar features. However, many potential differentials may be currently blurred, due to likely under-recognition of type $2 \mathrm{M}$ VWD by previous workers in the field, and incorporation of 
Table 4 Summary of similarities and differences for types 2A and 2M VWD

\begin{tabular}{|c|c|c|c|}
\hline & Similarities & Differences & Consequence/caveats \\
\hline $\begin{array}{l}\text { Laboratory } \\
\text { test features }\end{array}$ & $\begin{array}{l}\text { Both show similar levels of } \\
\text { VWF:Ag, FVIII, and VWF:RCo, } \\
\text { and similar VWF:RCo/Ag } \\
\text { ratios }\end{array}$ & $\begin{array}{l}\text { Loss of HMW VWF in } 2 A \text { VWD; } \\
\text { no loss of HMW VWF in } 2 M \\
\text { VWD. } \\
\text { May also show discrepancies in } \\
\text { VWF:CB and VWF:CB/Ag ratios } \\
\text { (low in } 2 A \text { VWD; but in type } 2 M \\
\text { maybe normal and similar to } \\
\text { type } 1 \text { VWD) }\end{array}$ & $\begin{array}{l}2 \mathrm{M} \text { VWD often misdiagnosed as } \\
\text { either } 2 \mathrm{~A} \text { or type } 1 \mathrm{VWD} \text {, and } \\
\text { occasionally the diagnosis is missed } \\
\text { and patients are not identified as } \\
\text { having VWD }\end{array}$ \\
\hline Clinical features & $\begin{array}{l}\text { Both show broadly similar } \\
\text { clinical symptoms }\end{array}$ & $\begin{array}{l}\text { 2A VWD may be a more } \\
\text { severe VWD than } 2 \mathrm{M} \text { VWD }\end{array}$ & $\begin{array}{l}\text { Historical lack of recognition of } 2 \mathrm{M} \\
\text { VWD means that differential clinical } \\
\text { features may fail to be identified and } \\
\text { will become increasingly recognized } \\
\text { following better discrimination of } 2 \mathrm{~A} \\
\text { versus } 2 \mathrm{M}\end{array}$ \\
\hline DDAVP response & $\begin{array}{l}\text { Both show similar } \\
\text { incremental rises in VWF:Ag } \\
\text { and FVIII, with lack of } \\
\text { response of VWF:RCo and of } \\
\text { VWF:RCo/Ag ratios. }\end{array}$ & $\begin{array}{l}\text { May show discrepancies in } \\
\text { response for VWF:CB and VWF: } \\
\text { CB/Ag ratios (lack of response in } \\
2 A \text { VWD; maybe good response } \\
\text { in } 2 M \text { VWD and similar to type } \\
1 \text { VWD) }\end{array}$ & $\begin{array}{l}\text { Able to utilize DDAVP response to } \\
\text { help differentially diagnose } 2 \mathrm{~A} \text { and } \\
2 \mathrm{M} \text { VWD }\end{array}$ \\
\hline $\begin{array}{l}\text { Therapy with VWF } \\
\text { concentrates }\end{array}$ & $\begin{array}{l}\text { Both currently treated } \\
\text { similarly with the same } \\
\text { concentrates and same } \\
\text { dosing }\end{array}$ & $\begin{array}{l}\text { Same concentrate and dosing } \\
\text { may not reflect ideal therapy for } \\
\text { all forms of VWD, including } 2 A \\
\text { and } 2 M \text { VWD }\end{array}$ & $\begin{array}{l}\text { Future recognition of } 2 \mathrm{M} \text { VWD may } \\
\text { identify more tailored therapies for } \\
2 \mathrm{~A} \text { and } 2 \mathrm{M} V \mathrm{VW} \text {, and this may differ } \\
\text { between } 2 \mathrm{~A} \text { and } 2 \mathrm{M}\end{array}$ \\
\hline
\end{tabular}

Abbreviations: Ag, antigen; CB, collagen binding; FVIII, factor VIII; R HMW, high molecular weight (VWF); RCo, ristocetin cofactor; VWD, von Willebrand disease; VWF, von Willebrand factor.

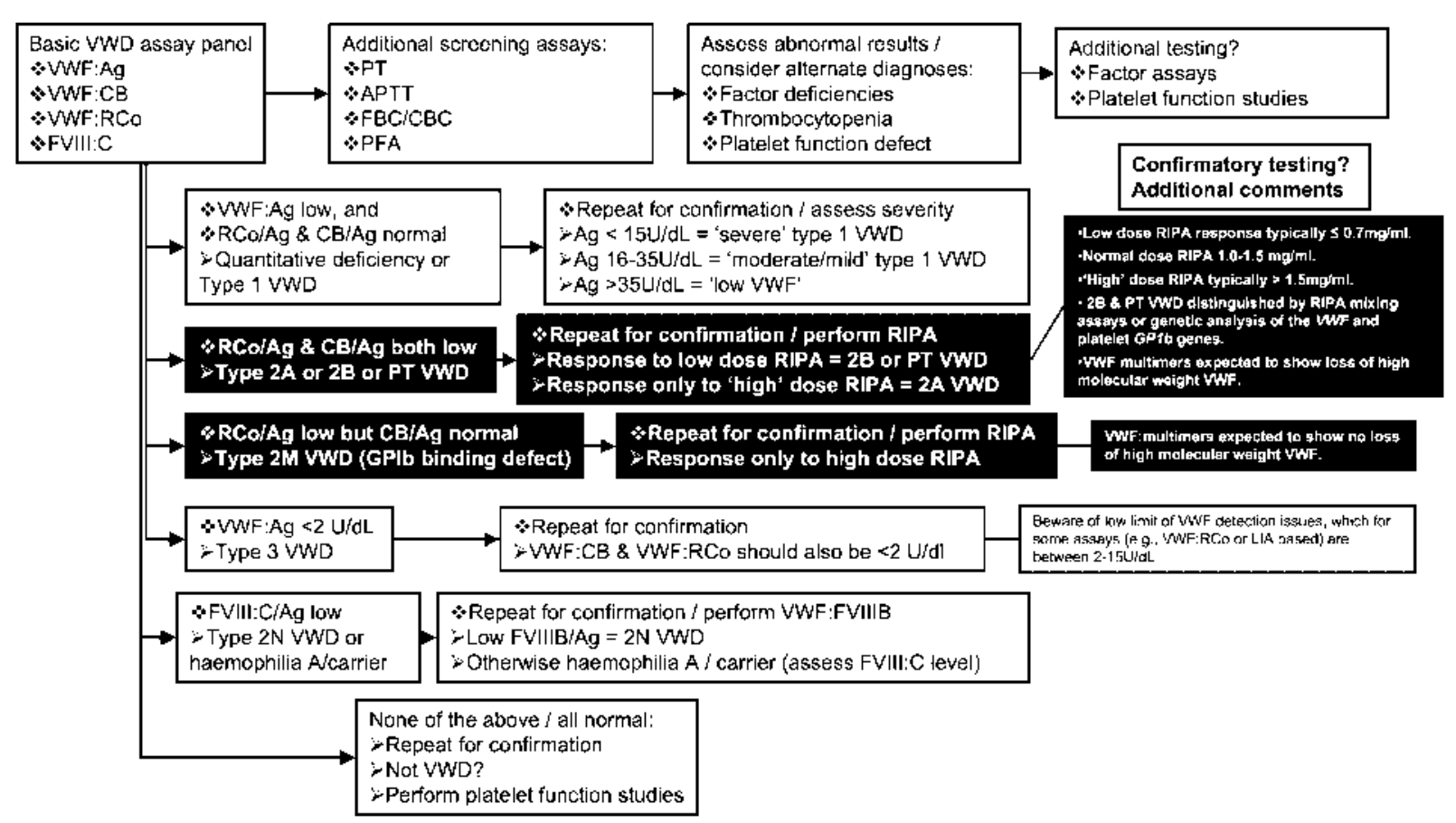

Fig. 5 An algorithm that describes our von Willebrand disease (VWD) diagnostic approach. The differential approach for types $2 A$ and $2 M$ VWD is specifically highlighted. 
these into type 2A (and type 1) VWD datasets. The few discriminatory studies performed suggest that $2 A$ VWD, as a group, may represent a more severe disorder than type $2 \mathrm{M}$ VWD, just as hemophilia A may define a more severe hemophilia than hemophilia $B$.

Therapeutic treatment of types $2 \mathrm{~A}$ and $2 \mathrm{M}$ VWD are currently "identical"-a DDAVP trial may be performed and in either case may or may not show sufficient responsiveness for a particular clinical purpose (e.g., minor surgery, dental extraction)-and if DDAVP responsiveness is not sufficient, both subtypes will be given VWF factor concentrates at the same "dose," to achieve the "same" target levels of FVIII and VWF:RCo. Moreover, additional therapeutic interventions (e.g., tranexamic acid) will also be similarly applied to both types of VWD.

However, current practice may not reflect the best possible clinical practice. In type 2A VWD, HMW VWF is missing, and thus a better therapeutic approach may be to target replacement therapy using HMW VWF; this may be possible with future formulations of $\mathrm{rVWF}^{66}$ In contrast, $2 \mathrm{M}$ VWD is not associated with loss of HMW VWF, and is instead reflective of VWF dysfunction(s) associated with VWF mutations that affect the ability of VWF to effectively function-the VWF in most $2 \mathrm{M}$ VWD cases fails to bind platelet GPIb. Thus, in a future landscape, different rVWF formulations may permit a treatment approach that addresses or treats such "specific" defects.

However, such possibility of better-tailored therapy can only eventuate if laboratories and clinicians better recognize the differential that $2 \mathrm{~A}$ and $2 \mathrm{M}$ VWD may represent. Better differential diagnosis of $2 \mathrm{~A}$ versus $2 \mathrm{M}$ VWD will also enable development of evaluable patient cohorts that will in turn permit better identification of differential clinical symptoms, as well as justifying future developments in rVWF development, therapy, and personalizing patient therapy.

\section{References}

1 Santagostino E, Fasulo MR. Hemophilia A and hemophilia B: different types of diseases? Semin Thromb Hemost 2013;39(7): 697-701

2 Sadler JE, Budde U, Eikenboom JC, et al; Working Party on von Willebrand Disease Classification. Update on the pathophysiology and classification of von Willebrand disease: a report of the Subcommittee on von Willebrand Factor. J Thromb Haemost 2006;4(10):2103-2114

3 Nichols WL, Hultin MB, James AH, et al. von Willebrand disease (VWD): evidence-based diagnosis and management guidelines, the National Heart, Lung, and Blood Institute (NHLBI) Expert Panel report (USA). Haemophilia 2008;14(2):171-232

4 Favaloro EJ. Von Willebrand disease: local diagnosis and management of a globally distributed bleeding disorder. Semin Thromb Hemost 2011;37(5):440-455

5 Favaloro EJ. Diagnosing von Willebrand disease: a short history of laboratory milestones and innovations, plus current status, challenges, and solutions. Semin Thromb Hemost 2014;40(5): $551-570$

$6 \mathrm{Ng}$ C, Motto DG, Di Paola J. Diagnostic approach to von Willebrand disease. Blood 2015;125(13):2029-2037

7 Lillicrap D. von Willebrand disease: advances in pathogenetic understanding, diagnosis, and therapy. Hematology (Am Soc Hematol Educ Program) 2013;2013(13):254-260
8 Favaloro EJ, Bodó I, Israels SJ, Brown SA. von Willebrand disease and platelet disorders. Haemophilia 2014;20(Suppl 4):59-64

9 Flood VH. Perils, problems, and progress in laboratory diagnosis of von Willebrand disease. Semin Thromb Hemost 2014;40(1):41-48

10 Yee A, Kretz CA. Von Willebrand factor: form for function. Semin Thromb Hemost 2014;40(1):17-27

11 Peyvandi F, Garagiola I, Baronciani L. Role of von Willebrand factor in the haemostasis. Blood Transfus 2011;9(Suppl 2):s3-s8

12 Jaffe EA, Hoyer LW, Nachman RL. Synthesis of von Willebrand factor by cultured human endothelial cells. Proc Natl Acad Sci U S A 1974;71(5):1906-1909

13 Sporn LA, Chavin SI, Marder VJ, Wagner DD. Biosynthesis of von Willebrand protein by human megakaryocytes. J Clin Invest 1985; 76(3):1102-1106

14 Favaloro EJ, Bonar R, Favaloro J, Koutts J. Diagnosis and management of von Willebrand disease in Australia. Semin Thromb Hemost 2011;37(5):542-554

15 Federici AB, Bucciarelli P, Castaman G, et al. Management of inherited von Willebrand disease in Italy: results from the retrospective study on 1234 patients. Semin Thromb Hemost 2011; 37(5):511-521

16 Rodgers SE, Lloyd JV, Mangos HM, Duncan EM, McRae SJ. Diagnosis and management of adult patients with von Willebrand disease in South Australia. Semin Thromb Hemost 2011;37(5):535-541

17 Iorio A, Oliovecchio E, Morfini M, Mannucci PM; Association of Italian Hemophilia Centres Directors. Italian Registry of Haemophilia and Allied Disorders. Objectives, methodology and data analysis. Haemophilia 2008;14(3):444-453

18 Penas N, Pérez-Rodríguez A, Torea JH, et al. von Willebrand disease R1374C: type 2A or 2M? A challenge to the revised classification. High frequency in the northwest of Spain (Galicia). Am J Hematol 2005;80(3):188-196

19 Riddell AF, Jenkins PV, Nitu-Whalley IC, McCraw AH, Lee CA, Brown SA. Use of the collagen-binding assay for von Willebrand factor in the analysis of type $2 \mathrm{M}$ von Willebrand disease: a comparison with the ristocetin cofactor assay. Br J Haematol 2002;116(1):187-192

20 Goodeve A, Eikenboom J, Castaman G, et al. Phenotype and genotype of a cohort of families historically diagnosed with type 1 von Willebrand disease in the European study, Molecular and Clinical Markers for the Diagnosis and Management of Type 1 von Willebrand Disease (MCMDM-1VWD). Blood 2007;109(1): 112-121

21 James PD, Paterson AD, Notley C, et al; ASSOCIATION OF HEMOPHILIA CLINIC DIRECTORS OF CANADA. Genetic linkage and association analysis in type 1 von Willebrand disease: results from the Canadian type 1 VWD study. J Thromb Haemost 2006; 4(4):783-792

22 James PD, Notley C, Hegadorn C, et al. The mutational spectrum of type 1 von Willebrand disease: results from a Canadian cohort study. Blood 2007;109(1):145-154

23 James PD, Notley C, Hegadorn C, et al; Association of Hemophilia Clinic Directors of Canada. Challenges in defining type 2M von Willebrand disease: results from a Canadian cohort study. J Thromb Haemost 2007;5(9):1914-1922

24 Cumming A, Grundy P, Keeney S, et al; UK Haemophilia Centre Doctors' Organisation. An investigation of the von Willebrand factor genotype in UK patients diagnosed to have type 1 von Willebrand disease. Thromb Haemost 2006;96(5):630-641

25 Laffan M, Brown SA, Collins PW, et al. The diagnosis of von Willebrand disease: a guideline from the UK Haemophilia Centre Doctors' Organization. Haemophilia 2004;10(3):199-217

26 Favaloro EJ, Bonar RA, Meiring M, et al. Evaluating errors in the laboratory identification of von Willebrand disease in the real world. Thromb Res 2014;134(2):393-403

27 Favaloro EJ, Bonar RA, Mohammed S, et al. Type 2M von Willebrand disease - more often misidentified than correctly identified. Haemophilia 2016; doi: 10.1111/hae.12903 
28 Arbelaez A, Niemann J, Freney R, et al. "Bleeding in the jungle”. Am J Hematol 2015;90(9):843-846

29 Favaloro EJ, Bonar R, Meiring M, Street A, Marsden K; RCPA QAP in Haematology. 2B or not 2B? Disparate discrimination of functional VWF discordance using different assay panels or methodologies may lead to success or failure in the early identification of type $2 \mathrm{~B}$ VWD. Thromb Haemost 2007;98(2):346-358

30 The online von Willebrand disease (VWD) database. . Available at: https://grenada.lumc.nl/LOVD2/VWF/variants.php?action=search_all. Accessed November 22, 2015

31 Favaloro EJ, Krigstein M, Koutts J, Brighton T, Lindeman R. Genetic testing for the diagnosis of von Willebrand disease: benefits and limitations. J Coagul Disord 2010;2:37-47

32 Favaloro EJ. Phenotypic identification of platelet-type von Willebrand disease and its discrimination from type $2 \mathrm{~B}$ von Willebrand disease: a question of $2 \mathrm{~B}$ or not $2 \mathrm{~B}$ ? A story of nonidentical twins? Or two sides of a multidenominational or multifaceted primaryhemostasis coin?. Semin Thromb Hemost 2008;34(1):113-127

33 Federici AB, Mannucci PM, Castaman G, et al. Clinical and molecular predictors of thrombocytopenia and risk of bleeding in patients with von Willebrand disease type 2B: a cohort study of 67 patients. Blood 2009;113(3):526-534

34 Favaloro EJ, Mohammed S, Koutts J. Identification and prevalence of von Willebrand disease type $2 \mathrm{~N}$ (Normandy) in Australia. Blood Coagul Fibrinolysis 2009;20(8):706-714

35 Favaloro EJ, Plebani M, Lippi G. Regulation in hemostasis and thrombosis: part I-in vitro diagnostics. Semin Thromb Hemost 2013;39(3):235-249

36 Chandler WL, Peerschke EIB, Castellone DD, Meijer P; NASCOLA Proficiency Testing Committee. Von Willebrand factor assay proficiency testing. The North American Specialized Coagulation Laboratory Association experience. Am J Clin Pathol 2011;135(6):862-869

37 Meijer P, Haverkate F. An external quality assessment program for von Willebrand factor laboratory analysis: an overview from the European concerted action on thrombosis and disabilities foundation. Semin Thromb Hemost 2006;32(5):485-491

38 Favaloro EJ. Detailed von Willebrand factor multimer analysis in patients with von Willebrand disease in the European study, molecular and clinical markers for the diagnosis and management of type 1 von Willebrand disease (MCMDM-1VWD): a rebuttal. J Thromb Haemost 2008;6(11):1999-2001, author reply 2002-2003

39 Adcock DM, Bethel M, Valcour A. Diagnosing von Willebrand disease: a large reference laboratory's perspective. Semin Thromb Hemost 2006;32(5):472-479

40 Flood VH, Gill JC, Friedman KD, et al; Zimmerman Program Investigators. Collagen binding provides a sensitive screen for variant von Willebrand disease. Clin Chem 2013;59(4):684-691

41 Favaloro EJ, Grispo L, Exner T, Koutts J. Development of a simple collagen based ELISA assay aids in the diagnosis of, and permits sensitive discrimination between type I and type II, von Willebrand's disease. Blood Coagul Fibrinolysis 1991;2(2):285-291

42 Favaloro EJ. An update on the von Willebrand factor collagen binding assay: 21 years of age and beyond adolescence but not yet a mature adult. Semin Thromb Hemost 2007;33(8):727-744

43 Favaloro EJ, Dean M, Grispo L, Exner T, Koutts J. von Willebrand's disease: use of collagen binding assay provides potential improvement to laboratory monitoring of desmopressin (DDAVP) therapy. Am J Hematol 1994;45(3):205-211

44 Favaloro EJ, Kershaw G, Bukuya M, Hertzberg M, Koutts J. Laboratory diagnosis of von Willebrand disorder (vWD) and monitoring of DDAVP therapy: efficacy of the PFA-100 and vWF:CBA as combined diagnostic strategies. Haemophilia 2001;7(2):180-189

45 Favaloro EJ, Mohammed S. Towards improved diagnosis of von Willebrand disease: comparative evaluations of several automated von Willebrand factor antigen and activity assays. Thromb Res 2014;134(6):1292-1300
46 Favaloro EJ, Mohammed S. Evaluation of a von Willebrand factor three test panel and chemiluminescent-based assay system for identification of, and therapy monitoring in, von Willebrand disease. Thromb Res 2015 (e-pub ahead of print). doi:10.1016/j. thromres.2015.12.010

47 Favaloro EJ. Collagen binding assay for von Willebrand factor (VWF:CBA): detection of von Willebrands Disease (VWD), and discrimination of VWD subtypes, depends on collagen source. Thromb Haemost 2000;83(1):127-135

48 Favaloro EJ. Evaluation of commercial von Willebrand factor collagen binding assays to assist the discrimination of types 1 and 2 von Willebrand disease. Thromb Haemost 2010;104(5): 1009-1021

49 Castaman G, Federici AB, Tosetto A, et al. Different bleeding risk in type $2 \mathrm{~A}$ and $2 \mathrm{M}$ von Willebrand disease: a 2-year prospective study in 107 patients. J Thromb Haemost 2012;10(4):632-638

50 Rodeghiero F. Von Willebrand disease: pathogenesis and management. Thromb Res 2013;131(Suppl 1):S47-S50

51 Tosetto A, Castaman G. How I treat type 2 variant forms of von Willebrand disease. Blood 2015;125(6):907-914

52 Curnow J, Pasalic L, Favaloro E. Treatment of von Willebrand disease. Semin Thromb Hemost 2016;42(2):133-146

53 Favaloro EJ, Franchini M, Lippi G. Biological therapies for von Willebrand disease. Expert Opin Biol Ther 2012;12(5):551-564

54 Mannucci PM, Kempton C, Millar C, et al; rVWF Ad Hoc Study Group. Pharmacokinetics and safety of a novel recombinant human von Willebrand factor manufactured with a plasma-free method: a prospective clinical trial. Blood 2013;122(5): 648-657

55 Gill JC, Castaman G, Windyga J, et al. Hemostatic efficacy, safety, and pharmacokinetics of a recombinant von Willebrand factor in severe von Willebrand disease. Blood 2015;126(17):2038-2046

56 Saccullo G, Makris M. Prophylaxis in von Willebrand disease: coming of age? Semin Thromb Hemost 2016;42(5):498-506

57 Kingman CE, Kadir RA, Lee CA, Economides DL. The use of levonorgestrel-releasing intrauterine system for treatment of menorrhagia in women with inherited bleeding disorders. BJOG 2004;111(12):1425-1428

58 Boey JP, Hahn U, Sagheer S, McRae SJ. Thalidomide in angiodysplasia-related bleeding. Intern Med J 2015;45(9):972-976

59 Goodeve AC. The genetic basis of von Willebrand disease. Blood Rev 2010;24(3):123-134

60 Lyons SE, Bruck ME, Bowie EJW, Ginsburg D. Impaired intracellular transport produced by a subset of type IIA von Willebrand disease mutations. J Biol Chem 1992;267(7):4424-4430

61 Rayes J, Hommais A, Legendre P, et al. Effect of von Willebrand disease type $2 \mathrm{~B}$ and type $2 \mathrm{M}$ mutations on the susceptibility of von Willebrand factor to ADAMTS-13. J Thromb Haemost 2007;5(2): 321-328

62 Sadler JE. Aortic stenosis, von Willebrand factor, and bleeding. N Engl J Med 2003;349(4):323-325

63 Kunicki TJ, Baronciani L, Canciani MT, et al. An association of candidate gene haplotypes and bleeding severity in von Willebrand disease type $2 \mathrm{~A}, 2 \mathrm{~B}$, and $2 \mathrm{M}$ pedigrees. J Thromb Haemost 2006;4(1):137-147

64 Favaloro EJ, Bonar R, Marsden K. Different bleeding risk in type 2A and 2M von Willebrand disease: a 2-year prospective study in 107 patients: a rebuttal. J Thromb Haemost 2012;10(7):1455-1458, author reply $1458-1460$

65 Federici AB, Mazurier C, Berntorp E, et al. Biologic response to desmopressin in patients with severe type 1 and type 2 von Willebrand disease: results of a multicenter European study. Blood 2004;103(6):2032-2038

66 Favaloro EJ. Towards personalized therapy for von Willebrand disease: future role of recombinant products. Blood Transfus 2016; DOI 10.2450/2016.0258-15 